\title{
PROFESIONALNA VOJSKA BREZ STROKOVNE AVTONOMIJE - ALI JE MOGOČE?
}

\section{PROFESSIONAL ARMED FORCES \\ WITHOUT PROFESSIONAL AUTHONOMY - \\ IS THIS POSSIBLE?}

Povzetek Podobno kot vojske drugih postkomunističnih držav se Slovenska vojska srečuje z izzivi profesionalizacije, pri čemer se avtor sprašuje, kakšen je njen končni cilj. Na podlagi pogledov različnih avtorjev, analiz o aktualni stopnji profesionalizacije Slovenske vojske in opravljene raziskave ugotavlja pomen strokovne avtonomnosti pri vzpostavljanju profesionalne vojske ter navaja škodljive učinke njenega omejevanja na učinkovitost vojske in zadovoljstvo vojaškega vrha. Članek prinaša pogled na razvojne faze profesionalizacije vojske in vojaško profesijo kot njen končni cilj, pri čemer je v ospredju vprašanje pristojnosti in odgovornosti vojske za lasten strokoven razvoj.

Ključne Profesionalizacija vojske, vojaška profesija, profesionalna avtonomija, vojaška besede stroka.

Abstract Like the armed forces of other post-communist countries, the Slovenian Armed Forces is facing, many challenges of the professionalization. The author questions its final goal. Based on other authors' opinions, analysis of the current level of professionalization of the Slovenian Armed Forces, as well as the results of his own research, he defines the significance of professional autonomy for the establishment of professional armed forces and points out how limited professional autonomy negatively impacts the military's effectiveness and the satisfaction of the military leadership thereof. The article provides an overview of different developmental phases in the military professionalization process and the military profession as its final goal, placing focus on the Slovenian Armed Forces' own responsibility and authority for its professional development.

Key words Professionalization, military profession, professional authonomy, military expertise. 
Uvod 28. maja 2002 je minister za obrambo določil projektno skupino za načrtovanje in izvedbo projekta Prehod na poklicno vojsko, dopolnjeno s prostovoljno rezervo (v nadaljevanju PROVOJ) (MO, 2002). Pet let pozneje je projektna skupina v zaključnem poročilu ugotovila, da je strategija, na podlagi katere se je izvajal projekt PROVOJ, dosežena (GŠSV, 2007). Z zaključkom projekta se profesionalizacija Slovenske vojske seveda ni končala in ostaja pot, polna izzivov, kot ugotavlja Kotnik v svoji analizi profesionalizacije SV (2012, str. 11-25). Čeprav so lahko mnenja o (pre)zgodnjem zaključku projekta različna, je mogoče razumeti poročilo projektne skupine, da je leta 2007 prenehala obstajati potreba po projektnem vodenju procesov, ki bi morali postati odgovornost organizacijskih enot in organov na Ministrstvu za obrambo, torej redna dejavnost podpore profesionalizaciji SV.

Pet let po zaključku projekta PROVOJ in deset let od opustitve naborništva ter prehoda na pretežno poklicno vojaško organizacijo lahko ugotovimo, da predlog projektne skupine o novem projektu »program razvoj« ni upoštevan. Ali je projektna organiziranost še (bila) potrebna ali ne, je stvar strokovne razprave, vsekakor pa se lahko strinjamo z mnenjem projektne skupine, da so potrebne politične usmeritve in določitev ciljev nadaljnje profesionalizacije SV. Usmeritve, ki jih po letu 2002 nismo zaznali, bi morale dati odgovor na vprašanje, ali naj se profesionalizacija razvija $\mathrm{v}$ smeri vojaške profesije ali pa ostane v okvirih projekta PROVOJ iz leta 2002, torej v okvirih normativno-statusne in kadrovske problematike SV. Na podlagi novih političnih usmeritev bi dobili odgovor tudi na vprašanje, ali morda obstaja politični konsenz za vzpostavitev razmeroma avtonomne vojaške profesije.

Namen članka je posredovanje pogleda na nadaljnjo profesionalizacijo SV in vzpostavljanje vojaške profesije kot končnega cilja. Pri tem bo posebna pozornost usmerjena $\mathrm{v}$ strokovno oziroma profesionalno avtonomijo, ki je pomemben dejavnik razvoja vsake profesije. V tem pogledu je članek nadaljevanje razprave Kotnika, Potočnika in Petkove iz prejšnjih številk Sodobnih vojaških izzivov o aktualni ravni profesionalizacije SV in dilemah njenega razvoja. V članku so ugotovitve o ravni strokovne avtonomije $\mathrm{SV}$ iz doktorske disertacije z naslovom Civilni nadzor in delovanje vojske (Furlan, 2012). Ugotovitve so pridobljene na podlagi deskriptivne metode in študij primerov v kadrovanju, opremljanju, usposabljanju in izobraževanju, financiranju, pripravljenosti ter delovanju SV. Za ugotavljanje pomena strokovne avtonomije je uporabljena statistična analiza odgovorov iz ankete, ki so jo izpolnili dosedanji načelniki Generalštaba SV in njihovi namestniki.

\section{PROFESIONALNA AVTONOMIJA KOT ELEMENT VOJAŠKE PROFESIJE}

Po Abrahamssonu je vojaška profesija »skupina tehnično in organizacijsko usposobljenih ekspertov $\mathrm{v}$ upravljanju nasilja, ki jih povezujejo skupno izobraževanje, skupna (korporativna) praksa in profesionalna etika« (v Jelušič, 1992, str. 145). Huntington je opisal tri temeljne značilnosti vojaške profesije: strokovnost (še posebno $\mathrm{v}$ ravnanju $\mathrm{z}$ ljudmi), odgovornost (ki presega denarno nagrado za 
opravljeno delo) in korporativnost (družbena skrb in predanost članom skupine) (v Feaver in Kohn 2001, str. 433). Jelušič med značilnosti vojaške profesije uvršča strokovnost, profesionalno avtonomijo, odgovornost častnikov, korporativnost, koncept neomejene službe (pripravljenost na žrtvovanje življenja), profesionalno kulturo in profesionalno etiko, sankcije skupnosti in profesionalno avtoriteto (1992, str. $146-162)$.

Kotnik je na podlagi proučevanja različnih avtorjev zbral te značilnosti vojaške organizacije: avtoritarnost (brezpogojna pokorščina), hierarhičnost, svojstven sistem stratifikacije (delitev na sloje - notranja struktura), centraliziranost, zaprtost (fizična in družbena), formaliziranost odnosov, avtonomija (selekcija, rekrutacija, socializacija), uniformnost in simbolika, profesionalnost, korporativnost in altruizem (nematerialne nagrade za stalno službo) (2002, str. 117-119).

Ameriška študija o stanju profesije v ameriški kopenski vojski poudarja, da si je status profesionalnosti treba zaslužiti in ohranjati zaupanje ter spoštovanje državljanov. Med značilnosti vojaške profesije uvršča zaupanje (državljanov do vojske, med institucijami, med vojaki in vojsko kot institucijo, medsebojno zaupanje pripadnikov), visoko strokovnost, tovarištvo, skrb za razvoj profesije in častno ter etično opravljanje vojaške službe (TRADOC, 2012, str. 4-6).

O vojaški profesiji in različnih pogledih nanjo pišeta tudi Potočnik (2012, str. 27-39) in Petek (2011, str. 81-97). Skupna značilnost različnih definicij je umeščenost strokovne ali profesionalne avtonomije v kontekst vojaške profesije, pri čemer so o njenem pomenu različna mnenja. Potočnik poudarja njeno vlogo kot enega izmed štirih stebrov, na katerem sloni vojaška profesija (2012, str. 35). Za druge je le ena izmed njenih sestavin. V vsakem pogledu pa je, kot ugotavlja Svetlik (v Kotnik, 2012, str. 13), »visoka avtonomija« neločljiv del vsake profesije. Svetlik navaja še pomembno značilnost profesije: »klienti sprejemajo njihovo ekspertizo in storitve kot nepogrešljive«. To pomeni, da zunaj profesije na področju stroke ni večje avtoritete ali, kot navaja Petek (2011, str. 90), je profesionalna avtonomija pogoj za doseganje profesionalne avtoritete ter za ugled in vpliv vojaške profesije, ki ji ga priznava okolje.

Da vojska potrebuje strokovno oziroma profesionalno avtonomijo, je skupna ugotovitev avtorjev, ki so proučevali civilno-vojaške odnose, obstajajo pa precej različni pogledi, kolikšna je potrebna in sprejemljiva raven avtonomije za obe strani v civilno-vojaškem odnosu; raven, ki bi bila razumljena kot pravična in bi zagotovila na eni strani stabilne civilno-vojaške odnose, na drugi pa učinkovito in zadovoljno vojsko. Za objektivnost civilnega nadzora nad vojsko je namreč pomembno, da civilne oblasti sprejemajo profesionalne vojaške kompetence in profesionalno avtonomijo ter nanje politično ne vplivajo (Huntington, 1998).

Koliko civilisti spoštujejo strokovno avtonomijo vojske, ima neposreden vpliv na vedenje vojske in njeno učinkovitost. Vpliva tudi na vojaško dojemanje poštenosti 
civilnega nadzora Čeprav se civilne in vojaške odgovornosti v nekaterih elementih prekrivajo, lahko razumemo strokovno avtonomijo kot cono omejenega gibanja za civiliste. Zanemarjanje njenega pomena lahko vodi v nezadovoljstvo vojske in povzroči deviacije v civilno-vojaških odnosih (Furlan, 2012b).

Burk je na primer ugotovil, da nastane kriza $\mathrm{v}$ civilno-vojaških odnosih vedno, ko civilisti ali vojaki delujejo zunaj svojih kompetenc. Takrat, ko opustijo svoje dolžnosti in odgovornosti ter poskušajo vplivati ali v ekstremnih primerih odločati na področjih, ki niso njihova domena. Ko na primer vojaško vodstvo vpliva na vladno politiko ali ko civilno vpliva na vojaško strategijo in taktiko (1998, str. 455-462). Hespring piše, da je v civilno-vojaških odnosih vedno konflikt, kadar politične avtoritete poskušajo neprekinjeno omejevati avtonomijo vojske, medtem ko poskuša vojska na različne načine preprečiti prizadevanja civilnih oblasti, da bi se vmešale v interne vojaške zadeve (1999, str. 557-577). Shiff omenja med oblikami subjektivnega civilnega nadzora primer, ko civilne elite onemogočajo vojski samostojnost do točke, ki pomeni grožnjo nacionalni varnosti (1996, str. 277-283).

S stališča civilnih oblasti je večna dilema, koliko avtonomije je še sprejemljive, da bi vojska po eni strani ostala pod nadzorom in ne bi pomenila grožnje, po drugi pa, da bi bili zagotovljeni pogoji za učinkovito izpolnjevanje njenega poslanstva. Torej, kolikšna je pravična raven profesionalne avtonomije. Bland na primer predlaga, da je treba omogočiti vojski raven pravične in dodeljene avtoritete na področjih, kot so vojaška doktrina, disciplina, operativno načrtovanje, notranja organiziranost, povišanja pod generalsko ravnjo ter taktično vodenje enot v operacijah (1999, str. 7-26). V okvir vojaških pristojnosti spadajo vojaška doktrina in taktika, usposabljanje, definiranje vojaških ciljev in vojskovanje (Gibson in Snider, 1993, str. 195). Desch (1999, str. 18) se ne strinja glede vojaške avtonomije na področju doktrine in podpira civilno odgovornost, ker je doktrina orodje, s katerim civilisti udejanjajo nadzor nad vojsko in lahko služi kot osrednja točka civilno-vojaškega dogovora o različnih vprašanjih (na primer uporaba vojske v mednarodnem okolju).

Primeri iz zgodovine kažejo, da je težko najti pravo raven profesionalne avtonomije. Feaver na primer navaja primer iz ameriške zgodovine o nepotrebnem vmešavanju politike v vojaško domeno, ko je predsednik na daljavo vplival na operativne odločitve poveljnikov v Vietnamu, ko je določal cilje bombardiranja, ter tako na doseganje vojaških ciljev (Feaver, 1996, str. 163). Deloma nasprotno mnenje ima Brodie, ki meni, da včasih civilisti bolje ocenjujejo posledice vojaškega delovanja, in navaja primer, ko so med kubansko raketno krizo leta 1962 generali vneto svetovali predsedniku vojaški napad kot edino sprejemljivo možnost (1973, str. 472-496). Podobni oceni se pridružujeta Feaver in Kohn, ki poudarjata, da je v primeru, ko je imela vojska najbolj svobodne roke, na primer nemška v prvi in japonska $\mathrm{v}$ drugi svetovni vojni, to povzročilo največjo škodo državam (2001, str. 437). Tudi Özbudun opozarja, da Huntingtonova vzročno-posledična povezava, da vojaška avtonomija vodi k profesionalnosti, ta pa vodi k politični nevtralnosti in prostovoljni podrejenosti civilistom, kar pomeni varen civilni nadzor nad vojsko, ne drži vedno. 
Primerjalne študije vojsk namrec kažejo, da so bile vojske, katerih značilnosti so kazale atribute profesionalnosti, sposobne izvesti vojaški udar ali so na druge načine odrekale podrejenost civilnim avtoritetam (2007, str. 3).

Avant med proučevanjem civilno-vojaških odnosov in delovanja vojske v ZDA in Veliki Britaniji ugotavlja, da politične institucije v ZDA omogočajo neko nestrinjanje vojske s civilisti in ji dajejo prostor za avtonomno oblikovanje lastne identitete in osredotočenja. To povzroča večjo veščino (in tudi stroške), vendar včasih slabšo odzivnost na nepričakovane grožnje in manjšo integriranost civilnih ciljev in vojaških načrtov; odzivnost je najboljša, ko grožnja ustreza pričakovanju ameriške vojske. Podatki so pokazali, da lahko civilisti, kadar se strinjajo s stvarmi, ki so pomembne za vojsko, prisilijo vojsko v spremembe. Toda v primerih, ko so za civiliste rešitve najbolj politično sprejemljive, je lahko počasnejša vojaška odzivnost. Po drugi strani britanske institucije spodbujajo civilno-vojaški dogovor in si prizadevajo za zniževanje vojaške profesionalne avtonomije. To najverjetneje spodbuja integriranost in odzivnost, vendar hkrati ovira razvoj veščin (in porabo denarja) glede na ZDA. Tako lahko institucionalne razmere, v katerih potekajo civilno-vojaški odnosi, sprožijo različna pričakovanja o vojaški učinkovitosti (2007, str. 100-101).

V iskanju odgovora o potrebni ravni vojaške profesionalne avtonomije bi se morali izogibati presoji različnih pogledov in se usmeriti na iskanje odgovorov na vprašanja, ali določena raven avtonomije vojski zagotavlja pogoje za učinkovito uresničevanje njenega poslanstva in ali zagotavlja njeno kredibilnost ter legitimnost v družbi. Ne glede na različne poglede je težko govoriti o profesionalnosti vojske, ki nima avtonomije v vojaški domeni in ni odgovorna za vojaške zadeve (Furlan, 2012b, str. 4).

\section{RAVEN STROKOVNE AVTONOMIJE SLOVENSKE VOJSKE}

Raziskava o značilnostih civilnega nadzora nad vojsko v Republiki Sloveniji po dvajsetih letih oblikovanja demokratičnih civilno-vojaških odnosov v samostojni državi je pokazala, da je nadzor učinkovit in sledi standardom ter praksam demokratičnih družbenih ureditev $\mathrm{z}$ daljšo tradicijo, vendar udejanjanje civilnega nadzora v praksi moteče vpliva na delovanje vojske. Nadzorni mehanizmi omejujejo svobodo delovanja načelnika Generalštaba SV in poveljnikov oziroma uveljavljanje njihovih odgovornosti pri izvajanju vojaških nalog in uporabi dodeljenih virov. Posledice takega civilnega nadzora so lahko upočasnjen tempo profesionalizacije Slovenske vojske in razvoja vojaške profesije, zmanjšanje verodostojnosti načelnika Generalštaba SV ter manjša učinkovitost poveljstev in enot, kar pomeni možnost zmanjšanja ugleda in legitimnosti v družbi (Furlan, 2012a).

Raziskava je potrdila navedbe nekaterih avtorjev v preteklosti, da v Sloveniji mehanizmi civilnega nadzora vojski omejujejo strokovno avtonomijo. Tudi podrobna analiza pristojnosti, ki jih ima načelnik Generalštaba SV, potrjuje, da Slovenska vojska ne uživa avtonomije na področjih, ki so navadno vojaška domena (glej preglednico 1). Tako na primer ne more povišati nobenega častnika in višjega vojaškega 
uslužbenca, določiti doktrin delovanja Slovenske vojske ter predpisati programov usposabljanja, taktičnih navodil in navodil za uporabo vojaške opreme in oborožitve.

Čeprav si avtorji niso enotni glede obsega strokovne avtonomije vojske in lahko najdemo upravičene razloge, da civilni nadzorniki »ne izpustijo iz rok« vojaške doktrine in poviševanja častnikov, pa nobena teorija ne govori v prid odločitvi, ki je uveljavljena z Zakonom o obrambi, da vojska ni odgovorna za definiranje svojega usposabljanja, taktične uporabe enot ter uporabe vojaške opreme in oborožitve. Zakon o obrambi je v resnici dodelil pristojnosti najvišjega vojaškostrokovnega organa ministru, čeprav jih ima sicer po istem zakonu Generalštab SV ${ }^{1}$. Da je omejevanje strokovne avtonomnosti moteč dejavnik delovanja vojske, prepoznava tudi predsednik republike - vrhovni poveljnik obrambnih sil, ko med drugim poudarja, da vojska potrebuje politični mir in polno strokovno avtonomijo (Barle, 2011, str. 4-9).

Preglednica 1: Pristojnosti načelnika Generalštaba SV

\begin{tabular}{|l|l|}
\hline Kadrovanje & $\begin{array}{l}\text { IMENOVANJE poveljnikov in namestnikov bataljonov in niže, imenovanje na } \\
\text { dolžnosti (razen brigadirjev in više) } \\
\text { POVIŠANJE podčastnikov } \\
\text { POTRJEVANJE napredovanj nižjih vojaških uslužbencev } \\
\text { ODLOČANJE o razporeditvi na drugo formacijsko dolžnost (razen brigadirjev in } \\
\text { generalov) }\end{array}$ \\
\hline Opremljanje & DOLOČANJE zahtev, podpisovanje študij in zahtevnikov \\
\hline Financiranje & $\begin{array}{l}\text { PODPISOVANJE pogodb iz dejavnosti in avtorskih pogodb ter odredb za izplačilo } \\
\text { ODLOČANJE o notranji razdelitvi finančnih virov v Slovenski vojski }\end{array}$ \\
\hline Usposabljanje & $\begin{array}{l}\text { PREDPISOVANJE metod in meril za ocenjevanje usposobljenosti, učnih načrtov in } \\
\text { preizkusnih programov vojaškega izobraževanja in usposabljanja }\end{array}$ \\
\hline Pripravljenost & PREDPISOVANJE meril za ugotavljanje pripravljenosti \\
\hline Delovanje & $\begin{array}{l}\text { POVELJEVANJE: izdaja aktov poveljevanja - odrejanje poslanstva in nalog } \\
\text { podrejenim poveljstvom in enotam, načrtov uporabe Slovenske vojske idr. }\end{array}$ \\
\hline
\end{tabular}

Da bi lahko ocenili, kolikšne so posledice te motnje v skupini drugih dejavnikov, ki negativno vplivajo na sposobnost SV, da učinkovito opravlja svoje poslanstvo, in povzročajo nezadovoljstvo vojske, sem vprašal za mnenje vojaški vrh; tiste, ki so najbolj odgovorni za stanje vojske in se najbolj neposredno spoprijemajo $\mathrm{z}$ mehanizmi civilnega nadzora. Čeprav statistično vzorec ni velik, ga imamo lahko za reprezentativnega $\mathrm{v}$ tej posebni skupini pripadnikov SV, saj prinaša sporočila vojaškega vrha². Odgovori so pokazali, da ima omejevanje strokovne avtonomnosti največji negativni vpliv oziroma je statistično najbolj moteč dejavnik za učinkovitost

\footnotetext{
Skladno z drugim odstavkom 42. člena Zakona o obrambi minister določa programe usposabljanja in vojaško strokovno literaturo, izdaja strokovna navodila ter ureja druga upravna in strokovna vprašanja organizacije ter dela vojske. Na podlagi 39. člena je Generalštab SV najvišji vojaški strokovni organ za poveljevanje.

2 Vprašanje o pomenu dejavnikov, ki negativno vplivajo na učinkovitost SV in zadovoljstvo vojaškega vrha, je bilo posredovano načelnikom Generalštaba SV, njihovim namestnikom in direktorjem štaba. Od skupno 18 se jih je odzvalo 13; pravilno izpolnjenih vprašalnikov, ki so upoštevani v analizi, je bilo 11 (61\%).
} 
SV in zadovoljstvo vojaškega vrha (glej diagram 1). Podroben vpogled v odgovore pa je razkril precejšnja razhajanja brigadirjev in generalov v razumevanju škodljivosti posledic tega omejevanja. Nekateri vidijo negativne vplive pri obeh, tako pri učinkovitosti kot zadovoljstvu, drugi dajejo večjo težo negativnim posledicam na zadovoljstvo kot na učinkovitost, v enem primeru pa anketirani ne daje velike negativne teže temu dejavniku (glej diagram 2).

Diagram 1:

Dejavniki, ki

negativno

vplivajo na

učinkovitost in

zadovoljstvo

vojske
Diagram 2: Vpliv omejevanja

strokovne avtonomnosti na učinkovitost in zadovoljstvo vojske

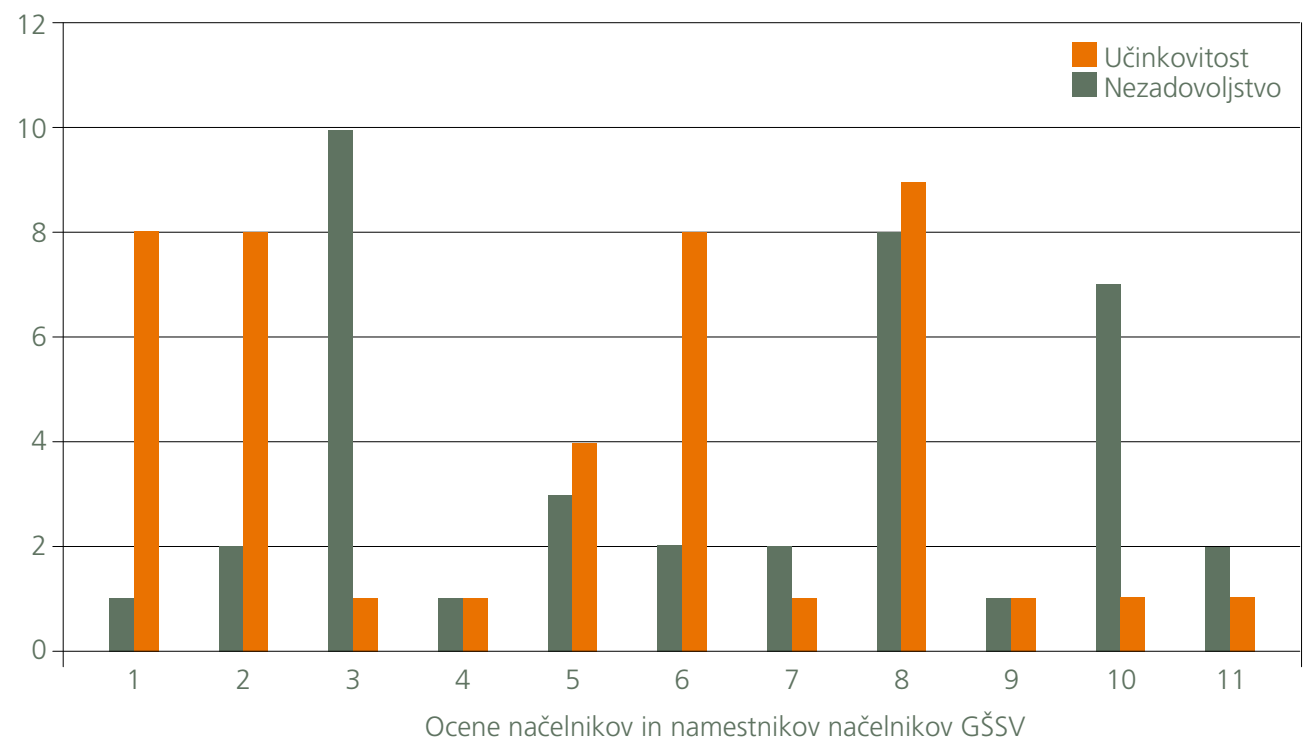

Podrobne politične usmeritve (mikromanagement)

Omejevanje razpolaganja z lastnimi viri

Pozne odločitve za uporabo vojske

Politične zahteve za spremembe vojaškega nasveta

Dodelitev neustreznih ali pomanjkljivih virov

Omejevanje svobode delovanja v vojaški sferi

Nejasne ali pomanjkljive naloge/usmeritve

Pomanjkljiva normativna ureditev uporabe vojske

Pravila delovanja

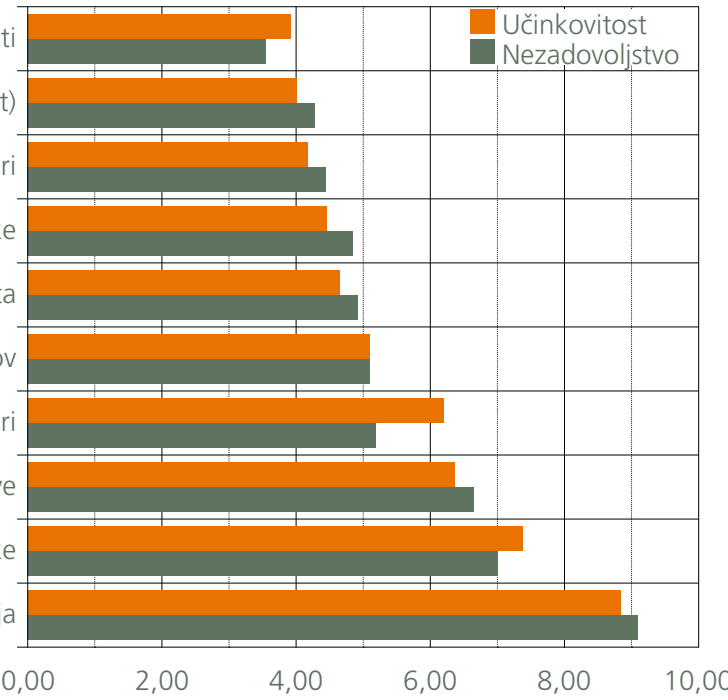

Ocene načelnikov in namestnikov načelnikov GŠSV 
Na podlagi mnenj vojaškega vrha lahko povzamemo, da (1) ima omejevanje strokovne avtonomnosti negativen vpliv na učinkovitost vojske, (2) povzroča nezadovoljstvo vojaškega vrha in (3) da ni enotnega pogleda vojaškega vrha na težo posledic, ki jo ima na stanje in delovanje vojske.

\section{VOJAŠKA PROFESIJA KOT (NE)DOSEGLIV CIL PROFESIONALIZACIJE SLOVENSKE VOJSKE}

Profesionalizacija SV je proces, ki traja od začetka njenega oblikovanja in se ni začel šele z ukinitvijo obveznega služenja vojaškega roka ter s projektom PROVOJ. Profesionalnost neke vojske ni odvisna od njene kadrovske strukture, temveč od načina delovanja in vedenja, znanja, strokovnosti, etičnosti idr. Razvojno gre profesionalizacija skozi tri faze. V prvi je osredotočena na poklicne dejavnike, v drugi na doseganje profesionalnosti, v tretji pa je cilj profesija. Zato je bila leta 2007 odločitev o zaključku projekta PROVOJ pravilna, saj je bil ta usmerjen v prvo fazo (ustvarjanje pogojev za pretežno poklicno vojaško organizacijo) in ni vseboval elementov, ki bi usmerjali nadaljnjo profesionalizacijo v vseh vsebinah, ki določajo profesionalnost vojske $^{3}$. Čeprav je nerešenih vprašanj še nekaj, na primer status vojakov v državni upravi, ima vojaški poklic svoje mesto v družbi in so ustvarjeni pogoji za vzpostavitev poklicne vojske, dopolnjene z rezervo, kar je bil cilj prve faze profesionalizacije.

$\mathrm{V}$ drugi fazi je profesionalizacija usmerjena $\mathrm{v}$ doseganje profesionalne vojske. Forster, Edmunds in Cottey (2002, str. 6-7) so definirali štiri značilnosti profesionalnosti: (1) jasna vloga v družbi (poslanstvo, odgovornosti, omejitve uporabe $\mathrm{v}$ domači politiki idr.), (2) strokovnost (standardi vstopa v vojsko, učinkovit sistem izobraževanja in usposabljanja, tehnična ekspertnost, znanje), (3) jasna odgovornost (delovno okolje, pretok informacij in povelj, spoštovanje mednarodnega prava, disciplina) in (4) napredovanje, ki temelji na dosežkih in kompetencah. Trdijo, da so profesionalne oborožene sile »idealna vrsta« in končno stanje ali cilj profesionalizacije. Profesionalizacija je potrebna, ker je civilni nadzor tako boljši in ker je vojska v izpolnjevanju poslanstva učinkovitejša.

Na kateri točki profesionalizacije je SV, so ugotavljali Petek (2011), Kotnik (2012) in Potočnik (2012). Tudi strateški pregled obrambnega resorja (SPOR) daje dober vpogled $\mathrm{v}$ doseženo raven in predvsem pomanjkljivosti (MO, 2009). Na podlagi njihovih ugotovitev in rezultatov raziskave (Furlan, 2012 a) lahko trdimo, da bi morala biti strokovnost v sedanjem trenutku najpomembnejša točka nadaljnje profesionalizacije SV. Glede na Forster-Edmunds-Cotteyeva merila profesionalnosti ima SV povsem izpolnjeni dve (vloga in odgovornost), eno (napredovanje) ostaja izziv, vendar je to, bolj kot normativno, vprašanje preglednosti in etičnosti uresničevanja v praksi. Strokovnost

\footnotetext{
3 Minister je v sklepu za oblikovanje projektne skupine določil naloge:

- vzpostavitev celovitega sistema upravljanja kadrov,

- pridobivanje in sprejem kadrov v vojaško službo,

- zadrževanje najboljših oziroma potrebnih kadrov v službi,

- vzdrževanje razmer za življenje in delo,

- pomoč in podpora nekdanjim pripadnikom SV in njihovim družinam (MO, 2002, str. 2).
} 
pa je pogoj profesionalnosti, za katerega si bo treba še precej prizadevati. Kot pravi Petek (2011, str. 90), ta ni na zadostni ravni in zato v tem trenutku ne moremo govoriti o vojaški profesiji, ki tudi ni potreben cilj. Strokovnost ni na ravni, ko bi okolje lahko prepoznavalo vojsko kot izključno profesionalno avtoriteto.

O ravni strokovnosti SV ne smemo oblikovati prenagljenih sklepov brez strokovno-znanstvene analize, dejstvo pa je, da nekatere opravljene analize govorijo o njenih pomanjkljivostih, na primer analiza vojaškega izobraževanja in usposabljanja v SPOR. S prizadevanji za odpravo ugotovljenih pomanjkljivosti bo SV vedno bolj strokovna in kompetentna, pri čemer bo pomembna strokovnost njenega delovanja na podlagi zakonitosti, pravil in etike. Vendar vsa prizadevanja in vse želje ne bodo dovolj, če ne bo tudi sprejela odgovornosti za vojaško stroko. Te zdaj na podlagi 42. člena Zakona o obrambi nima in zato najvišji vojaški strokovni organ (GŠSV) ne more predpisati programov usposabljanja ter taktičnih in tehničnih navodil. 39. člen Zakona je omejil strokovnost načelnika GŠSV samo na poveljevanje, za vse druge strokovne zadeve pa je odgovoren minister. Minister (politik) odloča o strokovnih vprašanjih vojske in predpisuje, kako na primer nekoga naučiti streljati ali uporabljati radijsko napravo, upravljati bojno vozilo ipd. Govorimo lahko o morebitnem (1) napačnem razumevanju civilnega nadzora, (2) tveganju politizacije vojaške stroke ali (3) nezaupanju v raven strokovnosti vojske. V vsakem primeru to pomeni, da vojska ni odgovorna in pristojna za vsa strokovna vprašanja in tako ne more postati popolnoma profesionalna.

Vojaška profesija je zaključna faza profesionalizacije in na podlagi predhodnih ugotovitev o težavah doseganja profesionalnosti SV je jasno, da je pot do vojaške profesije še toliko težja in je cilj precej odmaknjen v prihodnosti. Ali je profesija sploh cilj? Na to vprašanje bosta morali odgovoriti obe strani v civilno-vojaškem odnosu. Vojaki bodo odgovorili na to $\mathrm{z}$ dokazovanjem svoje profesionalnosti, civilisti pa s sprejemanjem in spoštovanjem te profesionalnosti. Da bi postal vojaški poklic prepoznaven v družbi kot profesija, bi moral izkazovati visoko raven strokovnosti in odgovornosti delovanja pripadnikov vojske, katerih etičnost in zakonitost ravnanja zagotavljata razmere, v katerih si pridobijo ugled, zaupanje ter s tem tudi profesionalno avtonomijo in avtoriteto. Pri tem avtonomijo razumemo kot avtonomijo profesionalcev, da samostojno, skladno s svojim strokovnim znanjem in običaji profesije, sprejemajo odločitve, za katere potem tudi odgovarjajo (Petek, 2011, str. 93). Tako lahko pri obravnavanju ključnih dejavnikov profesije govorimo o povezanosti odgovornosti, stroke in avtonomije, ki temeljijo na zakonih, pravilih in etiki (glej shemo 1).

Shema 1:

Atributi vojaške profesije

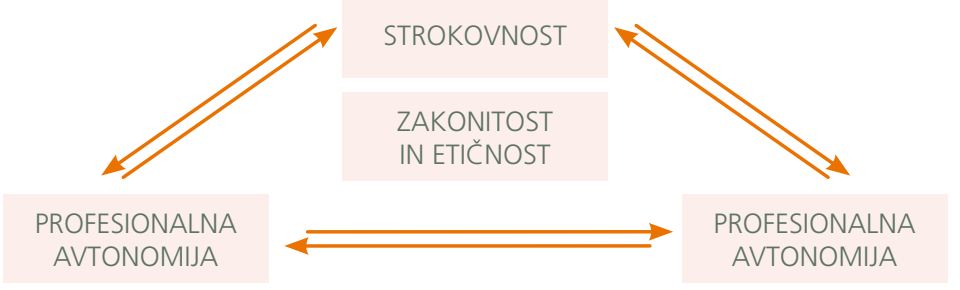


Z vpogledom v atribute vojaške profesije je na vprašanje, kdaj bo v Sloveniji vzpostavljena vojaška profesija, lahko odgovoriti. Takrat, ko bo vojska profesionalna in bo njena prepoznavnost priznana $\mathrm{v}$ javnosti in politiki, kar ji bo omogočilo profesionalno avtonomijo. Ta se namreč ne poklanja in tudi ne predpisuje, temveč se mora zaslužiti. Trikotnik odgovornost-strokovnost-avtonomnost ne opozarja samo, da brez strokovnosti in odgovornosti ne bo profesionalne avtonomije in s tem tudi ne profesije, temveč tudi na dejstvo, da se ob neodgovornem ali nestrokovnem delovanju ta avtonomija lahko hitro izgubi. Tako nas vprašanje profesije ponovno vrača na vprašanje možnosti, da SV postane profesionalna vojaška organizacija in na bistveno vprašanje njene strokovnosti. Brez dodeljene odgovornosti za strokovnost oziroma avtonomne pristojnosti za strokovne vojaške vsebine ne more postati profesionalna. Posledično ne more pridobiti profesionalne avtonomije in seveda tudi ne more razviti vojaške profesije.

Sklep Deset let po odločitvi o opustitvi obveznega služenja vojaškega roka in oblikovanju majhne, vendar učinkovite poklicne vojske, dopolnjene s prostovoljno rezervo, ugotavljamo, da je SV sredi procesa profesionalizacije, za katerega ni najbolj razvidno, v katero smer gre in v kaj je usmerjeno težišče prizadevanj. Da je profesionalna SV cilj, ki ga treba doseči, ni nobenega dvoma, saj je med drugim določen tudi v resoluciji Državnega zbora o splošnem in dolgoročnem programu razvoja in opremljanja SV do leta 2025. Politika je enotna glede profesionalizacije SV kot cilja, obstaja pa dvom, ali tudi glede profesionalizacije kot procesa, ki zahteva tudi spremembe statusa in normativnih podlag za delovanje vojske.

Analize aktualne ravni profesionalnosti postavljajo v ospredje strokovnost SV kot temeljni pogoj in glavno pomanjkljivost na poti doseganja profesionalizma. Ker je odgovornost za strokovna vojaška vprašanja dodeljena ministru, vojska nima odgovornosti za svoj strokovni razvoj in delovanje, kar pomeni tudi omejitev razvoja vojaškega profesionalizma in vojaške profesije. Posledično se lahko vpliv izvajalcev nadzora (politike) udejanja tudi na področju vojaške stroke, kar pa je nezdružljivo z načeli objektivnega civilnega nadzora in depolitizacije vojske. Omejevanje strokovne avtonomije je najbolj očiten primer uveljavljanja mehanizmov subjektivnega civilnega nadzora nad Slovensko vojsko.

Čeprav med avtorji ni enotnega mnenja, kolikšna je pravična raven strokovne avtonomije vojske, obstaja enoten pogled na neločljivo vojaško pristojnost na področju vojaške taktike in vojaškega usposabljanja. To je najmanjši skupni imenovalec in v zahodnih demokracijah ne poznamo primera, da vojska ne bi imela strokovne odgovornosti na teh dveh področjih. Tukaj ne gre za pravičnost ali velikodušnost civilnih oblasti, temveč za potrebo. Brez strokovne avtoritete na teh področjih ni vojaškega profesionalizma. Če je najnižja oziroma elementarna raven strokovne avtonomije za slovensko politiko nesprejemljiva, morda obstaja politični konsenz, da bo Slovenska vojska sicer pretežno poklicna, vendar ne bo popolnoma profesionalna in ne bo razvila vojaške profesije po vzoru nekih drugih poklicnih profesij, ali pa imamo 
še vedno opravka z zgodovinskim strahom, da vsakršna večja stopnja avtonomije pomeni grožnjo civilnemu nadzoru nad vojsko v Sloveniji. Ker njeno omejevanje povzroča nezadovoljstvo vojaškega vrha, obstaja večja verjetnost konflikta med civilnimi in vojaškimi oblastmi, kar lahko vodi v nestabilne civilno-vojaške odnose.

Dokler ne bo zavedanja, da je nujna zakonska sprememba na področju odgovornosti za stroko, ne bodo izpolnjeni vsi pogoji, da bi SV lahko dosegla ciljno raven profesionalnosti. Da si politika oziroma nosilci civilnega nadzora želijo profesionalno vojsko, ki bo delovala strokovno, verjetno ni dvoma. Vprašanje je le, na kateri stopnji bodo znali tudi zahtevati odgovornost za stroko v celoti in se bodo odrekli lastni odgovornosti, ki jo imajo na strokovnem vojaškem področju po Zakonu o obrambi, ter bodo odpravili možnosti politizacije vojaške stroke. Ko bo SV dodeljena odgovornost za stroko v celoti in jo bo znala uveljaviti v vseh vsebinah svojega delovanja, bodo izpolnjeni pogoji za doseganje profesionalne avtoritete in profesionalne avtonomije, s tem pa tudi za priznavanje vojaške profesije v družbi.

Profesionalizacija SV je najpomembnejši proces na obrambnem področju, neposredno povezan z vprašanji nacionalne varnosti, zato usmerjanja in vodenja profesionalizacije ne bi smeli prepusti stihiji ali naključjem. Po koncu projekta PROVOJ je čas, da dobi SV nove politične usmeritve za nadaljnji razvoj profesionalizacije, politika pa ugotovi, kako bo to podprla. Spremembe 39. in 42. člena Zakona o obrambi sta le prva, vendar nujna koraka.

1. Avant, Deborah, 2007. Political institutions and military effectiveness. Contemporary United States and United Kingdom. V Creating military power. The sources of military effectiveness, ur. Risa Brooks in Elisabeth Stanley. Stanford University Press. Str. 80-103.

2. Barle, Anže, 2011. Jedro suverenosti. Intervju s predsednikom republike. Revija Obramba. 2011, št. 1, str 4-9.

3. Bland, Douglas, 1999. A unified theory of civil-military relations. Armed Forces \& Society. 1999-26/ št. 1, str. 7-26.

4. Brodie, Bernard, 1973. War and politics. New York: MacMillan Publishing Co., Inc.

5. Burk, James, 1998. The logic of crisis and civil-military relations theory. Armed Forces \& Society. $1998-24 /$ st. 3, str. 455-462.

6. Desch, Michael, 1999. Civilian control of the military. The changing security environment. Baltimore: John Hopkins University Press, 1999, str. 18.

7. Feaver, Peter in Kohn, Richard, 2001. Soldiers and civilians. The civil-military gap and American national security. BCSIA Studies in International Security. Cambridge: The MIT Press.

8. Feaver, Peter, 1996. The civil-military problematique. Huntington, Janowitz and the question of the civilian control. Armed forces \& Society. 1996-23/št. 2, str. 149-178.

9. Forster, Anthony, Edmunds, Timothy in Cottey, Andrew, 2002. The challenges of military reform in postcommunist Europe. Palgrave Macmillan, str. 6-7.

10. Furlan, Branimir, 2012a. Civilni nadzor in delovanje vojske. Doktorska disertacija. FDV, 2012.

11. Furlan, Branimir, 2012b. Civilian control and military effectivenes: Slovenian case. Armed Forces \& Society. Objavljeno na http://afs.sagepub.com/content/early/2012/12/26/ 0095327X12459167, dne 10. 1. 2013. 
12. GŠSV, 2007. Zaključek projekta PROVOJ, št. 024-37/2007-1, z dne 22. 10. 2007.

13. GŠSV, 2009. Povzetek ključnih ugotovitev strateškega pregleda obrambnega resorja 2009. Št. 800-1/2009-196, z dne 20. 10. 2009.

14. Hespring, Dale, 1999. Samuel Huntington and communist civil-military relations. Armed Forces \& Society. 1999- 25/ št. 4, str. 557-577.

15. Huntington, Samuel, 1998. The soldier and the state. The theory and politics of civilmilitary relations. Boston: Harvard University Press, 13. izdaja.

16. Jelušič, Ljubica, 1992. Legitimnost vojaštva v sodobni družbi. Doktorska disertacija. Ljubljana: FDV.

17. Kotnik, Igor, 2002. Preoblikovanje oboroženih sil sodobnih evropskih držav. Znanstvena knjižnica 49. Ljubljana: FDV.

18. Kotnik, Igor, 2012. Profesionalizacija Slovenske vojske-cilj ali pot. Sodobni vojaški izzivi. 2012-14/ št.1, str. 11-25.

19. MORS, 2002. Sklep o oblikovanju projektne skupine PROVOJ, št. 802-00-8/2002-1, z dne 28. 5. 2002.

20. Özbudun, Ergun, 2007. Civilian control of the military: why and what? Study on democratic control of armed forces. European commission for democracy through law. Objavljeno na http://www.venice.coe.int/docs/2007/CDL-DEM2007005-e.asp, dne 11. 6. 2009.

21. Petek, Alenka, 2011. Profesionalna (slovenska) vojska?. Sodobni vojaški izzivi. 2011-13/ št. 2, str. 81-97.

22. Potočnik, Viktor, 2012. Vojaška profesija in profesionalni častnik včeraj, danes in jutri. Sodobni vojaški izzivi. 2012-14/ št. 1, str. 27-39.

23. Shiff, Rebecca, 1996. Concordance theory: a response to recent criticism. Armed Forces \& Society. 1996-23/st. 2, str. 277-283.

24. US TRADOC, 2012. The army profession campaign. Annual report. Norfolk, str. 4

25. Zakon o obrambi. Uradni list RS, št. 103/04-UPB-1. 